\title{
How the Solow Growth Model Changes with Effective Use of Natural Resources ${ }^{i}$
}

\author{
Kristína Gardoňová \\ Institute of Economic Research, Slovak Academy of Sciences, Slovakia
}

Copyright $(2016$ by authors, all rights reserved. Authors agree that this article remains permanently open access under the terms of the Creative Commons Attribution License 4.0 International License

\begin{abstract}
There are many extensions of the Solow model. We took one of the most recent ones that deals with the environment - Romer's model with environmental aspects, in which he discusses the effects of land and natural resources' limitations on economic growth. Furthermore, we took the theoretical knowledge of Weil, who says that the drag caused by the limited amount of natural resources can be outweighed by the spur created by technological progress with the help of substitution of more expensive production factors with cheaper, less valuable, ones. In this paper we put these two thoughts together, creating a model based on Romer's analysis with inclusion of a new parameter effective use of natural resources that grows at a rate of technological progress. We show that theoretical results of the Solow model still hold, however we provide a better explanation of the factors that limit or reinforce the economic growth.
\end{abstract}

Keywords Solow Model, Economic Growth, Natural Resources, Technological Progress, Substitution, Effective, Environment

\section{Introduction}

The theoretical Solow model, as it was presented by Solow in 1956, studies the economic growth through a neoclassical production function of a Cobb-Douglas type. It attempts to explain long-run economic growth by means of accumulation of capital, labor and population growth; furthermore by increases in productivity, which is referred to as technological progress. Solow [1] comes to a conclusion where countries are richer with a higher rate of savings and poorer with a higher rate of population growth. These conclusions seem to meet the evidence also provided by Mankiw, Romer and Weil [2], however, the major problem of the Solow model is the exogenous nature of technological progress, and moreover, the exogenous rates of savings and population growth. The first part of the paper provides a thorough overview of the development of the literature from the basic Solow model to its many extensions with technological progress, human capital, environmental aspects, and presentation of solutions to the three major problems of the Solow model mentioned beforehand.

In the second part this paper argues that the predictions of Solow model are right, which was also proved by Mankiw, Romer and Weil in their article, but we will look more closely at the Romer's extension of the Solow model with environmental aspects, where he included land and natural resources and argued that the limitations posed by land and non-renewable resources do not hamper the economic growth, because they can be outweighed by technological progress on one hand and by process of substitution of production factors on the other.

Weil [3] argued that in history we saw many examples of substitution of expensive production factors with cheaper ones. The price of natural resources reflects its value and therefore the limited amount of natural resources should not constitute a problem, even the resource intensive production should not get more expensive. Furthermore, as land exists in limited amount on Earth, its price should go up with time, however, we see that the rent is decreasing over time and so, the limitations of supply of land should not hamper economic growth either.

In our work we took Weil's theoretical knowledge and plugged it into Romer model with environmental extension. We created a model similar to the Romer's one, but including the effective use of natural resources, which was not present in the base model. We asked ourselves a question: Why should we only count with the amount of natural resources and land invested in production, when we live in the world of technological advancements and we are really solving the question of how effectively we use our resources?

Finally, we draw conclusions on how the drag caused by resources' limitations can be outweighed by the spur that technological progress produces which was discussed by Weil in theory, but never written in formulas.

\section{Literature Review}


Year 1956 was a milestone in the theory of economic growth. Robert M. Solow and Trevor W. Swan wrote an article about long-run economic growth, creating a wave of interest in this issue. Solow directly reacted to articles published by Harrod and his neutral effect of technological growth. Neokeynesian models of Harrod and Domar had unsolved problems, like unstable nature of balanced rate of growth and controversies between guaranteed rate of growth and natural rate of growth. Neoclassical approach to these problems is very different. Growth is looked upon only from the production factors side. The basic macroeconomic factors are capital and labor that can be combined in different proportions according to technological and economic conditions of a country, i.e. there is a mutual substitution of production factors. Solow model tries to explain how accumulations of capital, technical and technological progress determine economic growth. It takes a Cobb-Douglas production function to relate total inputs to total outputs of an economy.

The first basic growth model was without technological progress and without rate of population growth. The economy had a fixed amount of capital. Labor and capital are inputs to the production process. The final product, created by means of initial labor and capital, is homogenous and divided into consumption and savings. Propensity to save is given exogenously, whereas all savings are invested. In the next period, the capital base is bigger by the amount of gross investments; however, a part of capital will depreciate in the production process. The problem of the model was that it did not explain economic growth. Even though the capital increases, it is combined with the same number of labor forces; every additional unit of capital brings less and less additional output and therefore less and less additional savings. The depreciated part of capital is constant, and so, at one point all savings will cover depreciation. The gross investment will equal depreciation, net investment will be zero, capital will remain constant and the economy will stop to grow.

Therefore, Solow extended the model with exogenous technological progress that grows independently of the economy's growth. Economy converges to the steady state, where product, capital and consumption pre unit of effective labor are constant. That means that product, capital and consumption per capita, or per unit of labor, grow at a rate of technological progress. Macroeconomic aggregates product, capital and consumption are growing at a rate of a sum of rate of technological progress and rate of population growth, i.e. rate of growth of units of effective labor. The conclusion of Solow-Swan model is that long-run economic growth equals to the rate of technological progress and does not depend on the propensity to save. The changes in propensity to save will be reflected in changes in capital and product in steady state. However, we see that the model was still not able to explain well enough the long-run economic growth; the core problem of the model was the exogenous nature technological progress, which would exist also under conditions if no new technology was added to the production process [4]. Other weaknesses of the model are exogenous nature of savings rate and rate of population growth, which caught the attention of other authors.

Robert Solow took the condition of constant propensity to save from the Harrod model. But why would not households want to save a different amount of income in different period? They would probably increase their utility by doing so. Solow in his article stated that the interest rate is the price of capital, which equals to the marginal rate of capital that is decreasing - the less capital, the higher the interest rate. Assuming that the economy starts off with a capital base lower than the one in steady state, the capital base will grow and the interest rate will decrease. If a lower interest rate motivates households to save less, then it can be assumed that the propensity to save will decrease with time.

Frank Ramsey [5] in his article $A$ Mathematical Theory of Saving gave a solution to Solow problem, almost 30 years before its assignment. He endogenised the propensity to save by means of optimization theory. The most commonly used method is based on Pontryagin's maximum principle, but a simpler way is to derive the Euler's equation and work with the rate of time preference. The result of Ramsey-Cass-Koopmans model, in which the authors endogenised the saving rate is the phase diagram, which shows the possible ways for the economy to get to the steady state, and the points, where attending the steady state is no longer possible.

Another problem of the Solow model was the exogenous nature of population growth. Becker and Barro [6] in their article called A Reformulation of the Economic Theory of Fertility included elements like altruism, choices of fertility and consumption that come the maximization of a dynastic utility function, to show that real interest rates and growth rates of consumption per capita are unrelated in the long run. They argued that fertility in open economies depends positively on the world interest rate and the degree of altruism, and negatively on the rate of technological progress and the growth rate of social security. Therefore, they endogenised the rate of population growth, which is no longer constant, as it was in the Solow model.

Despite of the two solutions to the problems of the Solow model described above, there was a major problem - the exogenous rate of technological growth. Authors like Romer, Weil and Mankiw were the leading authors of endogenous theory of growth. However, it was Lucas [7], who first advised to add human capital to the Solow model in his article On the Mechanics of Economic Development. He was searching for reasons for differences in income in different parts of the world. Lucas resumed the work of Uzaw from 1964 and created a neoclassical model with two sectorsproduction sector that produces consumption and investment goods and education sectors. Physical and human capital are used in the production sector, whereas only human capital is invested in the education sector. Lucas-Uzaw two sector models tries to find the optimum way how to combine these two sectors in order for the economy to grow optimally without decreasing households utility. 
Mankiw, Romer and Weil took the Solow model seriously. In their article $A$ Contribution to the Empirics of Economic Growth they endogenised the technological progress by adding human capital to the model, which is a parameter of effectiveness of labor and technological progress. Furthermore, they tested the conclusions of the Solow model, and by adding the human capital to the model, better explained the results as why some countries are poor and why some are rich, thus confirming the Solow's predictions that countries grow slower with higher rate of population growth and faster with higher rate of savings.

There are many other extensions of the Solow growth model, such as Romer's [8] extension with environmental aspects that includes land and natural resources and concludes that limitations given by the limited amount of land and non-renewable resources on Earth do not hamper the economic growth, because, as Weil stated, substitution and technological progress outweigh the negative effects of those limitations.

\section{Analysis of Economic Growth with the Incorporation of Natural Resources}

In this paper we concentrate our attention on the problem of resource limitations and how they affect the economic growth, so let us take the fundamental macroeconomic model, the Solow model, from Romer's analysis, to show how natural resources can be incorporated into the analysis of economic growth. Natural resources along with pollution are absent from the Solow model. However, this phenomenon has become increasingly important as the perpetually rising output will eventually deplete resources. The basic Solow is an exogenous growth model. It takes the following form,

$$
Y(t)=K(t)^{\alpha}(A(t) L(t))^{1-\alpha}
$$

where the long-run economic growth is explained by capital accumulation $(\mathrm{K})$, labor $(\mathrm{L})$, population growth (n) and technological progress (A), which is an exogenous variable and can also be referred to as increases in productivity or effectiveness of labor. In production process we have to bear in mind the continuous time that is required for the model to have an explanatory character. Variables are therefore defined at every point in time and grow at constant rates.

$$
\begin{gathered}
\dot{K}(t)=s Y(t)-\delta K(t) \\
\dot{L}(t)=n L(t) \\
\dot{A}(t)=g_{A}(t)
\end{gathered}
$$

Dot over a variable denotes a derivative with respect to time; $n$ and $g$ are exogenous parameters. Since output $(\mathrm{Y})$ is divided between consumption and investment, the fraction of output devoted to investment is $s$-savings. Savings is also an exogenous variable that grows at a constant rate. One unit of output devoted to investment yields one unit of new capital, however, this unit of capital depreciates at rate $\delta$.

In our analysis we want to include natural resources and land. We therefore extend the Cobb-Douglas type production function (1) to include new variables, $R$, which denotes resources used in production, $B$ that denotes effectiveness of resources' use and $T$ that denotes the amount of land.

$$
\begin{aligned}
& Y(t)=K(t)^{\alpha}[B(t) R(t)]^{\beta} T(t)^{\gamma}[A(t) L(t)]^{1-\alpha-\beta-\gamma}, \\
& \alpha>0, \quad \beta>0, \quad \gamma>0, \quad a+\beta+\gamma<1 .
\end{aligned}
$$

Dynamics of the variables are same as before (2); however we have to state the dynamics of new variables. Resources used in production, $\mathrm{R}$, grow at a negative rate because their amount in the production process gets smaller with time, as they exist in fixed quantity, mainly the non-renewable ones.

$$
\dot{R}(t)=-b R(t), \quad b>0
$$

Effectiveness of resources' use, $B$, grows at the rate of technological progress, because it is a parameter of effectiveness of natural resources. Natural resources extraction and processing completely depend on technological progress, because their use gets more effective as the technology gets better.

$$
B^{\prime}(t)=g_{B} B(t)
$$

The amount of land, $T$, on earth is fixed; therefore the quantity used in production does not change over time.

$$
\dot{T}(t)=0
$$

Without including $R, T$ and $B$ in our analysis, $K / A L$ would converge to some value according to which it is possible to analyze the behavior of an economy. With the new variables included we have to ask ourselves a question, whether there can be a balanced growth path. The assumption is that $A, B, L$, $R, T$ grow at constant rates. In order to achieve the balanced growth path, $K$ and $Y$ must grow at a constant rate. If they are to grow at a constant rate, $K / Y$ must be constant, that is, the growth rates of $K$ and $Y$ they must be equal. The growth rate of $K$ taken from (2) is

$$
\frac{\dot{K}(t)}{K(t)}=s \frac{Y(t)}{K(t)}-\delta
$$

Taking the production function (5) we search for the growth rate of $Y$ on a balanced growth path that would be equal to growth rate of $K$. First step is to take logs of both sides of the equation,

$$
\begin{aligned}
& \ln Y(t)=\alpha \ln K(t)+\beta[\ln B(t)+\ln R(t)]+ \\
& +\gamma \ln T(t)+(1-\alpha-\beta-\gamma)[\ln A(t)+\ln L(t)]
\end{aligned}
$$

Secondly, we differentiate both sides of the equation with respect to time, as the time derivative of the log of a variable equals its growth rate, 


$$
\begin{aligned}
& g_{Y}(t)=\alpha g_{K}(t)+\beta\left[g_{B}(t)+g_{R}(t)\right]+ \\
& +\gamma g_{T}(t)+(1-\alpha-\beta-\gamma)\left[g_{A}(t)+g_{L}(t)\right],
\end{aligned}
$$

for simplification, we use the growth rates of $L, A, R, T$ used earlier in (3), (4), (6) and (8).

$$
\begin{aligned}
& g_{Y}(t)=\alpha g_{K}(t)-\beta\left(b-g_{B}\right)+ \\
& +(1-\alpha-\beta-\gamma)\left(n+g_{A}\right) .
\end{aligned}
$$

If the economy is on a balanced growth path, we have to impose $g_{K}=g_{Y}$ on (9), we get

$$
g_{Y}^{b g p}=\frac{(1-\alpha-\beta-\gamma)\left(n+g_{A}\right)-\beta\left(b-g_{B}\right)}{1-\alpha}, 1-\alpha>0
$$

where $g_{y}^{b g p}$ denotes the growth rate of $Y$ on the balanced growth path. When looking at the equation (13), we can see that if resources and land were not incorporated into the model, the growth rate of $Y$ would be exactly the same as growth rate of capital stock $K$, which is $n+g$ in order to hold $k$ (quantity of capital in units of effective labor) steady. Moreover, we see that technological progress plays a crucial role, as it influences more parameters, namely $L$ and $R$. We will see later on, that it also influences the drag itself. $b$ $g_{B}$ can be either bigger than or smaller than 0 . If the rate of use of natural resources in production process is bigger than the rate at which technology increases the effectiveness of use of natural resources, then the growth rate of $Y$ on the balanced growth path is smaller. If, on the other hand, $b$ is bigger than $g_{B}$, the $g_{y}^{b g p}$ is larger.

We determined the value of growth rate of $Y$ on the balanced growth path, but this does not tell us whether the economy converges to this state. We find this by intuition: if the growth rate of $K$ exceeds its balanced growth path value, the growth rate of $Y$ does as well, but by less than $K$. This is because the growth rate of $K$ is determined by $\alpha$, and so $\alpha$ is negatively correlated with the growth rate of $Y$. $Y$ grows slower than $K$, because it is determined by more factors $(n,-b$, $g$ ). Following our intuition, $Y / K$ is falling. Knowing that growth rate of $K$ is $s(Y / K)-\delta$ implies that if $Y / K$ is falling, the growth rate of $K$ is falling, too. Therefore we can say that the growth rate of $K$ converges to its balanced growth path value, and so the economy converges to its balanced growth path also after including natural resources and land variables.

\section{Why Resource Limitations Do Not Prevent Economic Growth?}

The limited amount of natural resources should at first sight be a drag to growth. On the other side, technological progress is a spur to growth. If the spur created by technological progress is larger than the drag exerted by resource limitations, then there is sustained growth in output per worker [8]. Furthermore, when we look at the prices of natural resources, they tend to decline over time. However, if natural resources were scarce in production and their amount was limited, the prices, as an indicator for value, should go up. But this is not the case today. If a country is resource-rich, falling natural resource prices can severely harm its economy, like we see the example of Russia today. Russia's economy greatly depends on energy exports, as it is the world's largest producer of crude oil and second largest producer of dry natural gas. The revenue from oil and natural gas production and exports accounts for more than half of Russia's federal budget revenue [9]. On the other hand, falling natural prices benefit economies that are scarcely endowed with natural resources and where production takes place, like it is the case of Switzerland. Although Switzerland has almost no natural resources, this fact has not prevented its economy to grow. The country went through a period of massive industrialization, which took place during European postwar reconstruction from 1950s to 1970s. Nowadays Switzerland has the $3^{\text {rd }}$ highest Human Development Index of a value of 0.930 , that indicates "very high human development", and it is the $19^{\text {th }}$ largest economy in the world [10]. It is, therefore, arguable that the spur created by technological progress has outweighed the drag caused by lack of natural resource endowment in the country.

In this section we will firstly look at how big is the drag caused by natural resources limitations in an economy and secondly we will state two most important reasons as why the resource limitations do not prevent economic growth.

In order to count the amount of drag, we have to change the assumptions of $T$ and $R$, so they do not pose limitations on growth. We have to replace them with new assumptions:

$$
\begin{gathered}
\dot{T}(t)=n_{T}(t) \\
\dot{R}(t)=n_{R}(t)
\end{gathered}
$$

Land and resources now grow at the rate of population growth; therefore they do not create any drag on growth. The economy on a balanced growth path in the hypothetical case without limitations looks as follows:

$$
\tilde{g}_{Y}^{b g p}=\frac{(1-\alpha-\beta-\gamma)\left(n_{L}+g_{A}\right)+\beta\left(n_{R}+\gamma n_{T}\right)}{1-\alpha}
$$

To calculate the amount of drag caused by resource limitations we have to subtract the growth rate of income per capita $(Y / L)$ on the balanced growth path from the growth rate in the hypothetical case without limitations. 


$$
\begin{aligned}
\operatorname{Drag} & =\widetilde{g}_{Y / L}^{b g p}-g_{Y / L}^{b g p} \\
& =\frac{(1-\alpha-\beta-\gamma)\left(n+g_{A}\right)+\beta\left(n+g_{B}\right)+\gamma \mathrm{n}-\left[(1-\alpha-\beta-\gamma)\left(n+g_{A}\right)-\beta\left(n-g_{B}\right)\right]}{1-\alpha} \\
& =\frac{\beta\left(b-g_{B}\right)+\beta n_{R}+\gamma n_{T}}{1-\alpha} \\
& =\frac{\beta n_{R}+\gamma n_{T}+\beta\left(b-g_{B}\right)}{1-\alpha}
\end{aligned}
$$$$
\text { If } \quad n_{R}=n_{T}=n=n_{A}
$$

then,

$$
\tilde{g}_{Y}^{b g p}-g_{Y}^{b g p}=\frac{(\beta+\gamma) n+\beta\left(b-g_{B}\right)}{1-\alpha}
$$

We see that the growth drag gets bigger as the following variables grow or represent a large share: resources' share $(\beta)$, land's share $(\gamma)$, the rate that resource use is falling $(b)$, the rate of population growth $(n)$, the technological progress $(g)$ and capital's share $(\alpha)$. If technological progress had no effect on natural resources, i.e. if we erased $B$ from the equation (5), the drag would look as of Romer's analysis:

$$
\begin{aligned}
\operatorname{Drag} & =\widetilde{g}_{Y / L}^{b g p}-g_{Y / L}^{b g p} \\
& =\frac{(1-\alpha-\beta-\gamma) g-[(1-\alpha-\beta-\gamma) g-\beta b-(\beta+\gamma) n]}{1-\alpha} \\
& =\frac{\beta b+(\beta+\gamma) n}{1-\alpha}
\end{aligned}
$$

Since we think that $B$ is a valuable parameter in our equation, the final drag incorporates $g_{B}$, the rate of growth of resources saving, and thus gives the latter a crucial role to play in the amount of drag an economy is getting by the limitations of natural resources. If technological progress is high, more substitution takes place and this substitution can lower the drag.

In other words, if $b<g_{B}$ the drag is smaller, because by increasing $g_{B}$, the effectiveness of use of non-renewable resources, the drag is reduced.

If we want to quantify the drag in real economy it is possible to do so, as resources are traded in markets. Nordhaus [11] was the first one who attempted such quantification and found out that only a quarter of the growth drag stems from land limitations and the rest is due to limited amount of energy resources. He found the value of $0.2(\beta+\alpha)$, to be interpreted as the percentage by which an economy is losing on growth each year due to natural resource limitations. His conclusion is that the growth drag is important, but not large enough to be very significant.

The fact that natural resources are scarce is incontrovertible. Why is that their price is not going up steeply over time? There are two main reasons to this substitution and technological progress. In the eyes of a consumer a substitute good is a product that a consumer

perceives as similar or comparable, or that exerts the same function. Nicholson [12] put it more formally: if A and B are substitutes and the price of $\mathrm{A}$ rises, the demand for $\mathrm{B}$ increases. The same happens with natural resources. In the history we saw numerous examples of resource substitution, as the coal gas replaced whale oil as a source of illumination or electricity, gas and coal replaced wood as a source of heating. This relationship is reflected by the price elasticity of demand, which is the percentage change in the quantity of a demanded good over the percentage change in the good's price. Price is the indicator for value. If a product or a natural resource is much demanded, it has a high value. Weil argues that if there is no close substitute for a good, the good's price goes up with rising demand. Its price elasticity of demand will be close to zero. However, if a close substitute exists, with a slight increase in price the demand for the good falls. Such a good will be elastic, i.e. will have price elasticity of demand bigger than 1. Moreover, price elasticities of demand are smaller in the short run than in the long run, as in a longer term people are able to accommodate to a new situation. In the short-run it is not possible to switch to technologies that require a different natural resource use. This process takes some time, and therefore a substitution takes longer. It is clear that the key to economizing on the use of a resource is price. So, if a resource begins to run short, its price begins to rise; this will induce substitution from it. For illustration, in the $18^{\text {th }}$ and $19^{\text {th }}$ century, Belgium was well known for its coal extraction. Surface occurrences of coal were very abundant, deep mines were not required and opening of new canals made shipment of extracted coal easy, even to neighboring countries. Abundance of coal during the Industrial revolution kept its price low. However, by the late $19^{\text {th }}$ century entrepreneurs had to go deeper and deeper and the seams were becoming exhausted. Coal became scarcer, exploitation costs higher, and so went up the prices [13]. Gradually, new, more effective and less pollutant natural resources were found, and nowadays Belgium is the seventh EU country that went coal-free, as it closed its last coal power plant this year. The extraction of coal is no longer economical to exploit since late $20^{\text {th }}$ century.

Closely related topic to substitution of natural resource is technological progress. Without it, substitution would not be possible. With every change in the use of a natural resource, new technology is inevitable. We saw numerous examples of new technologies that eased resource constraints that were impeding economic growth. So far, the limitations of natural resources and land have been out weighted by technological 
progress, i.e. the drag on economic growth caused by limited amount of natural resources has been lower than the spur created by technological progress. Prices again are the key to the system of creation of a new technology. When prices of natural resources go up, they signal that there is need for a new technology to be invented. A country of technological advancement and innovations, Japan, has very inadequate natural resources to support its growing demand and large population. Japanese post-war economic miracle happened between 1950s and 1990s. Nowadays, Japan is the $3^{\text {rd }}$ largest economy and an example how a country can assimilate its technology by means of research and innovations to changing inputs into production, whether it has been in the automotive, electronics or semiconductors sector. However, the world's most famous example of a country that was able to change the structure of its economy rapidly is South Korea. Having very little natural resources, in 1960s South Korean development was comparable to that of Ghana, an African standard nation. Today, South Korea is one of the world's leading industrial nations, a large exporter of semiconductors, automotive, computers, petrochemicals and high tech electronics. It is the $11^{\text {th }}$ largest economy, despite of being heavily dependent on imported natural resources. In this case, the spur created by technological progress during the period of country's massive industrialization called Miracle on the Hangang river between 1960s and 1990s, outweighed the drag caused by very limited natural resources [14].

\section{Conclusions}

Solow model did not take into account the natural resources and land, although they can pose limitations to growth due to their fixed quantity on earth. We tried to show how natural resources and land, if incorporated into the Solow model, would affect the economic growth. We took the Romer model with environmental extensions as a base model. Then we added another parameter to it - the effectiveness of use of natural resources which grows at the rate of technological progress that influences the costs of extraction and processing of natural resources.

Doing this, we have shown the influences on the drag of economic growth itself. On the other hand, we concluded that the limitations posed by natural resources are not very significant, around $0.2 \%$ of GDP per year, which is not big, but not negligible either. A reason for this is that in the economy there exist two processes through which an economy maximizes its use of scarce resources - substitution and technological progress. If a natural resource is price elastic, a hike in price will drive consumers towards other natural resource. However, for this to happen a switch in

\footnotetext{
i The research for this paper was financially supported by VEGA project n.2/0005/16 Economic and geopolitical causalities of the changing global energy scene and their implications for the EU's position in the global economy.
}

technology is needed, where a technological progress plays its crucial role.

Moreover, the drag caused by natural resources limitations have been out weighted by the spur created by technological progress. As far as technological progress is moving forward at the same or higher rate that natural resources are used up or depleted, the limitations posed by natural resources fixed amount on earth will not have a significant effect on economic growth. This is also shown by decreasing prices of natural resource over time, as prices are an indicator of value.

\section{REFERENCES}

[1] R. Solow. A Contribution to the Theory of Economic Growth, Quarterly Journal of Economics, 65-94, 1956.

[2] Mankiw, Romer, Weil. A Contribution to the Empirics of Economic Growth, Quarterly Journal of Economics, 407-437, 1992.

[3] D. Weil. Economic Growth, Prentice Hall, 2009.

[4] J. Lisy. Economic growth and economic cycle, Iura Edition, Bratislava, 2011.

[5] F. Ramsey. A Mathematical Theory of Saving, The Economic Journal, Vol. 38, No. 152, 543-559, 1928.

[6] Becker, Barro. A Reformulation of the Economic Theory of Fertility, Quarterly Journal of Economics, Vol. CIII, No. 412, 1-25, 1998.

[7] Lucas. On the Mechanics of Economic Development. Journal of Monetary Economics, Vol. 22, No 1, 3-42, 1988.

[8] D. Romer. Advanced Macroeconomics, McGraw-Hill, 2012.

[9] EIA. Russia is world's largest producer of crude oil and lease condensate. 2016. Available online at: http://www.eia.gov/to dayinenergy/detail.cfm?id=22392

[10] World Bank. GDP ranking. World Bank.org. 2016. Available online at:http://data.worldbank.org/data-catalog/GDP-rankin g-table

[11] W. Nordhaus. Lethal model 2: The Limits to Growth Revisited, Yale University, 1972.

[12] W. Nicholson. Microeconomic Theory: Basic Principles and Extensions, 2011.

[13] W. Parker, N. Pounds. Coal and Steel in Western Europe. The influence of Resources and Techniques on Production, Bloomington: Indiana University Press, pp 381, 1957.

[14] The Korean Economy - the Miracle on the Hangang River. Korea.net. Available online at: http://www.korea.net/About Korea/Economy/The-Miracle-on-The-Hangang

In developing the ideas presented here, I have received helpful input from prof. Ing. Mikulas Luptacik, PhD., for which I am very thankful. 